\title{
Dexmedetomidine Associated Lung Cancer Proliferation and Tumor Growth is Prevented by $\beta$-Caryophyllene: Role of AMPK Activation and PGC-1 $\alpha /$ TFAM Over Expression
}

\author{
Dan Wang ${ }^{1 \#, ~ D a z h i ~ L o n g " \#, ~ J i e g a n g ~ Z h o u ¹, ~ Z i q i a n g ~ D o n g ~}{ }^{1}$, Guiming Huang
}

10.18805/IJAR.BF-1431

\begin{abstract}
Background: Dexmedetomidine has been reported to induce anti-apoptotic effects and metastatic progression in lung cancer. In the current investigation, the effect of $\beta$-Caryophyllene on dexmedetomidine induced cell proliferation and apoptosis of lung cancer cells and tumor growth in mice was studied.

Methods: A549 cell line was cultured with either dexmedetomidine alone or together with $\beta$-Caryophyllene for $24 \mathrm{~h}$ and analysed for cell proliferation with MTT assay. ELISA based kit was used to determine apoptotic DNA fragmentation. Western blotting was used to determine expression levels of target proteins. The induction of experimental lung tumor in rat model was achieved through the injection of A549 tumor cells subcutaneously into the middle left side of the mice after anesthetization with pentobarbital $(35 \mathrm{mg} / \mathrm{kg})$ at $2.8 \times 10^{6}$ cells in $400 \mu \mathrm{l}$ of PBS.

Result: We found that $\beta$-Caryophyllene exerts the anti-proliferative effects on A549 cells. Furthermore, $\beta$-Caryophyllene significantly prevents apoptotic cell death and causes up-regulation of PGC-1 $\alpha$ and TFAM compared to dexmedetomidine treated cells. We observed that $\beta$-Caryophyllene suppressed tumor development in mice significantly compared to dexmedetomidine treated group without changing body weight.
\end{abstract}

Key words: Apoptosis, $\beta$-caryophyllene, Dexmedetomidine, Lung cancer, Tumor growth.

\section{INTRODUCTION}

Dexmedetomidine is a commonly used sedative agent during perioperative period. It has been reported that dexmedetomidine induce anti-apoptotic effects and metastatic progression in different cancers like lung cancer (Xia et al. 2016; Cui et al. 2015). It is worth to note that the molecular mechanism responsible for the dexmedetomidine associated cancer induction is still unknown.

Isolation of biologically active compounds from nature and their use in cancer therapy has emerged vastly in past decade (Graham et al., 2000). Such active compounds are aimed to impact different signaling pathways in cancer cells so to induce apoptosis and death of target cells Hsu, (Singh and Schuster 2004). Use of such naturally obtained compounds is presenting a great scope in the field of cancer research and therapy (Cragg and Pezzuto 2016). $\beta$ caryophyllene, a naturally obtained product from has been reported to induce apoptosis and cell death in various cancer cell lines (Amiel et al. 2012).

Mitochondria are known as the "powerhouse" of the cell because they create the vital energy required for cellular functions. PGC-1 (peroxisome proliferator-activated receptor gamma co-activator 1) has emerged as an important factor for biogenesis of mitochondria (Scarpulla 2011) LeBleu et al. (2014). PGC-1 has been found to change the transcriptional activity of numerous critical mitochondrial genes, leading to an increase in mitochondrial DNA (Puigserver et al., 1998).

Despite the fact that numerous chemotherapy procedures are utilized to treat human sarcomas, however, for high-grade sarcomas such therapies have proven
'Department of Anesthesiology, Ganzhou People's Hospital, Ganzhou, Jiangxi, 341000, China.

'Department of Urology, Ji'an Central Hospital, Ji'an, Jiangxi, 343000, China.

\#These authors contributed equally to this work.

Corresponding Author: Guiming Huang, Department of Anesthesiology, Ganzhou People's Hospital, Ganzhou, Jiangxi, 341000, China. Email: 154093876@qq.com

How to cite this article: Wang, D., Long, D., Zhou, J., Dong, Z. and Huang, G. (2021). Dexmedetomidine Associated Lung Cancer Proliferation and Tumor Growth is Prevented by $\beta$-Caryophyllene: Role of AMPK Activation and PGC-1 $\alpha /$ TFAM over Expression. Indian Journal of Animal Research. DOI: 10.18805/IJAR.BF-1431.

Submitted: 23-08-2021 Accepted: 13-12-2021 Online: 16-01-2022

ineffective (Bajpai and Susan 2016). Several treatment options against high-grade sarcomas have previously been reported. Reduced mitochondrial numbers have been associated to neoplastic transformation and/or tumor progression, including apoptosis resistance, in a number of investigations (Masuike et al. 2018). PGC-1Q controls the activities of several nuclear receptors and transcriptional factors responsible for mitochondrial biogenesis (Canto and Auwerx 2009). A lower number of mitochondria have been reported in osteosarcoma. Forced increase of mitochondria number in human sarcoma cell lines has been reported to induce mitochondrial apoptosis and therefore cell death (Xie et al., 2013). Changes in copy number of mitochondrial DNA 
(mtDNA) have been well reported in human cancers (O'Hara et al., 2019; Reznik et al., 2016). Furthermore, mitochondrial dysfunction has been associated with cancer progression via TFAM (mitochondrial transcription factor A) silencing (Araujo et al. 2018). The present study aims to investigate the role of $\beta$-Caryophyllene on proliferation, apoptosis and tumor growth associated with dexmedetomidine in lung cancer.

\section{MATERIALS AND METHODS}

\section{Cell culture and treatment}

Human lung carcinoma cells (A549) was acquired from ATCC (American type culture collection). Cells were grown in culture for 24h in DMEM (Dulbecco's modified eagle medium) mixed with 10\% FBS (Fetal bovine serum) and supplemented with antibiotic solution $(100 \mathrm{U} / \mathrm{ml})$. Cells were either left untreated or treated with Dexmedetomidine (1nM) alone or together with $\beta$-Caryophyllene $(4 \mu \mathrm{M})$ in 12 -well plates. All the experimental work has been carried out in Ganzhou People's Hospital (Ganzhou, Jiangxi, China) and Ji'an Central Hospital (Ji'an, Jiangxi, China) from January 2019 to July 2021.

\section{MTT assay}

Human lung alveolar epithelial cells (A549) $\left(1 \times 10^{3}\right)$ were cultured in 96-well plates for $24 \mathrm{~h}$ and treated with different amount of Dexmedetomidine or together with $\beta$ Caryophyllene for $12 \mathrm{~h}$. It was followed by MTT assay as performed by Fu et al. (2020). Per cent cell value was taken from the results of triplicate reactions.

\section{Apoptosis assay}

To carry out the apoptotic assay, A549 cells were cultured in 96 -well plates for $24 \mathrm{~h}$. Cells were either treated with Dexmedetomidine treatment alone or together with $\beta$ Caryophyllene for $12 \mathrm{~h}$. Cell death assay kit (ELISA based) was used to determine apoptosis (manufacturer's instructions were followed).

\section{Wound healing assay}

For wound healing assay purposes, A549 cells were cultured in 12-well plate overnight. With the help of $10 \mu$ tip, a scratch was created on the monolayer cells. After scratch, cells were washed once with culture media to remove floating cells. Cells were kept untreated or either treated with dexmedetomidine alone or together with $\beta$-Caryophyllene for $12 \mathrm{~h}$. Images of fresh scratch were captured immediately with the help of a digital camera. After treatment completion, cells were washed thrice with culture media and followed by capturing of pictures of the scratch. The scratch area was calculated using Image-Pro Plus software (Media Cybernetics, USA). Cell migration was determined by calculating the scratch closure.
The wound was observed at 0 and $24 \mathrm{~h}$, which were recorded as W0 and W24, respectively, using a light inverted microscope (magnification, x40). Cell migration (\%) was calculated according to the formula:

$$
\frac{\text { WO-W24 }}{\text { W0 }} \times 100
$$

\section{Protein extraction}

Preparation of A549 cell lysate was achieved using lysis buffer (NP-40). To prevent proteolysis of cell lysate, Halt Protease Inhibitor Cocktail (Thermo Scientific) was used. Centrifugation (3000 rpm for $10 \mathrm{~min}$ ) of cell lysate was performed to obtain supernatant. Bradfords assay was used to determine protein concentration.

\section{Western blotting}

Protein samples were prepared as described by Waza et al (2012). Detection of target proteins were determined using specific antibodies: anti-p-AMPKa (Thr172), anti-AMPKa, anti-PGC-1 $\alpha$, anti-TFAM, anti-caspase-3/9, anti-PARP and a-GAPDH. HRP conjugated anti rabbit was used as secondary antibody and incubated at room $37^{\circ} \mathrm{C}$ for $2 \mathrm{~h}$. $E C L$ kits was used to visualize the protein bands in the membrane and analyzed using FR-200 system (Shanghai FURI Technology).

\section{Quantitative PCR (qPCR)}

A549 cells treated with Dexmedetomidine treatment alone or together with $\beta$-Caryophyllene for $12 \mathrm{~h}$ were subjected to the quantification of mitochondrial DNA (mtDNA) relative to nuclear DNA. Extraction of genomic DNA was carried out using DNA extraction kit (Sigma-Aldrich). It was followed by PCR amplification of mtDNA using specific primers (Table 1).

\section{Animal model of liver cancer}

$B A L B / C$ nude mice (30 in number) were used for the present study. The experimental liver tumor model was created in the mice as described earlier. In the present study, animals were followed up for 40 days with 4 groups of rats as follows, Group 1 as control with vehicle (Sham); Group 2 rats with liver tumor induced (model), Group 3 rats administered with Dexmedetomidine $(0.5 \mathrm{mg} / \mathrm{kg}$ per day) (Dex) for 2 weeks prior to liver tumor induction and Group 4 rats administered with Dexmedetomidine $(0.5 \mathrm{mg} / \mathrm{kg}$ per day) and $\beta$-Caryophyllene (20 mg/kg per day) (Dex $+\beta$-Caryophyllene) for 2 weeks prior to liver tumor induction and continued even after liver tumor induction till the end of the experimental periods.

For the induction of liver tumor, A549 tumor cells were injected subcutaneously into the middle left side of the mice after anesthetization with pentobarbital $(35 \mathrm{mg} / \mathrm{kg})$ at $2.8 \times$ $10^{6}$ cells in $400 \mu$ l of PBS. Normal saline doses were given to sham and model mice groups. A regular body weight

Table 1: PCR amplification of mtDNA using specific primers.

\begin{tabular}{lll}
\hline Target & Forward primer $\left(5^{\prime}-3^{\prime}\right)$ & Reverse primer $\left(5^{\prime}-3^{\prime}\right)$ \\
\hline mtDNA & GCAGATTTGGGTACCACCCAAGTATTGACTCACCC & CATGGAGAGCTCCCGTGAGTGGTTAATAGGGTGATAG
\end{tabular}


check-up was performed for every day till the experiment was finished (Fu et al., 2020).

\section{Statistical analysis}

SPSS software was used to carry out statistical analysis. Experimental values were given as mean and standard error of mean. Statistical significance was measured with ANOVA and for multiple comparisons purposes post-hoc test was used $(P<0.05$ as statistically significant).

\section{RESULTS DISCUSSION}

$\beta$-Caryophyllene inhibits cell proliferation in dexmedetomidine treated cells

There is an urgent need to look for new anti-tumor targets for treating lung tumor successfully (Liu et al., 2017). The present study was carried out to look for the possible role of $\beta$-Caryophyllene against dexmedetomidine induced cell proliferation in lung cancer cells. First of all, we investigated the impact of $\beta$-Caryophyllene on proliferation of dexmedetomidine treated lung cancer cell line using MTT assay (Wang et al., 2018). As shown in Fig 1, $\beta$-Caryophyllene treatment significantly inhibited proliferation of A549 cells compared to dexmedetomidine treatment and control.

\section{$\beta$-Caryophyllene induces apoptosis in dexmedetomidine} treated cells

Cell survival and death are mainly decided by the expression dynamics of pro- and anti-apoptotic proteins. Expression levels of pro-apoptotic proteins like caspases get up- regulated during cell death (Bartke et al., 2001). To look for the underlying mechanism of $\beta$-Caryophyllene-induced death in A549 cells, western blotting was carried out (Fig 2A). As shown in (Fig 2B) caspase-3/9 levels and cleaved PARP gets increased after $\beta$-Caryophyllene treatment in dexmedetomidine challenged cells. Densitometry analysis (Fig 2C) showed that $\beta$-Caryophyllene treatment increases expression levels of caspase- 3 by 2.8 and 2 fold compared to dexmedetomidine treatment and control respectively. Expression level of caspase- 9 was increased by 2.7 and 1.4 fold with $\beta$-Caryophyllene treatment compared to dexmedetomidine treatment and control respectively. Similarly, it was observed that $\beta$-Caryophyllene increases

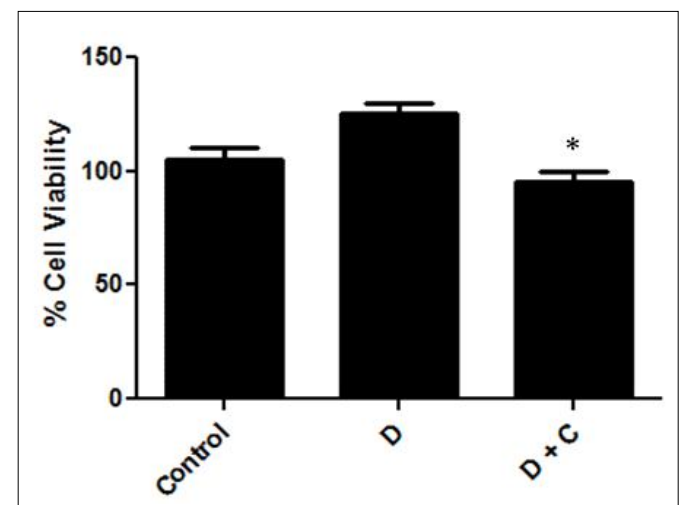

Fig 1: Effect of $\beta$-Caryophyllene on cell proliferation in dexmedetomidine treated cells.

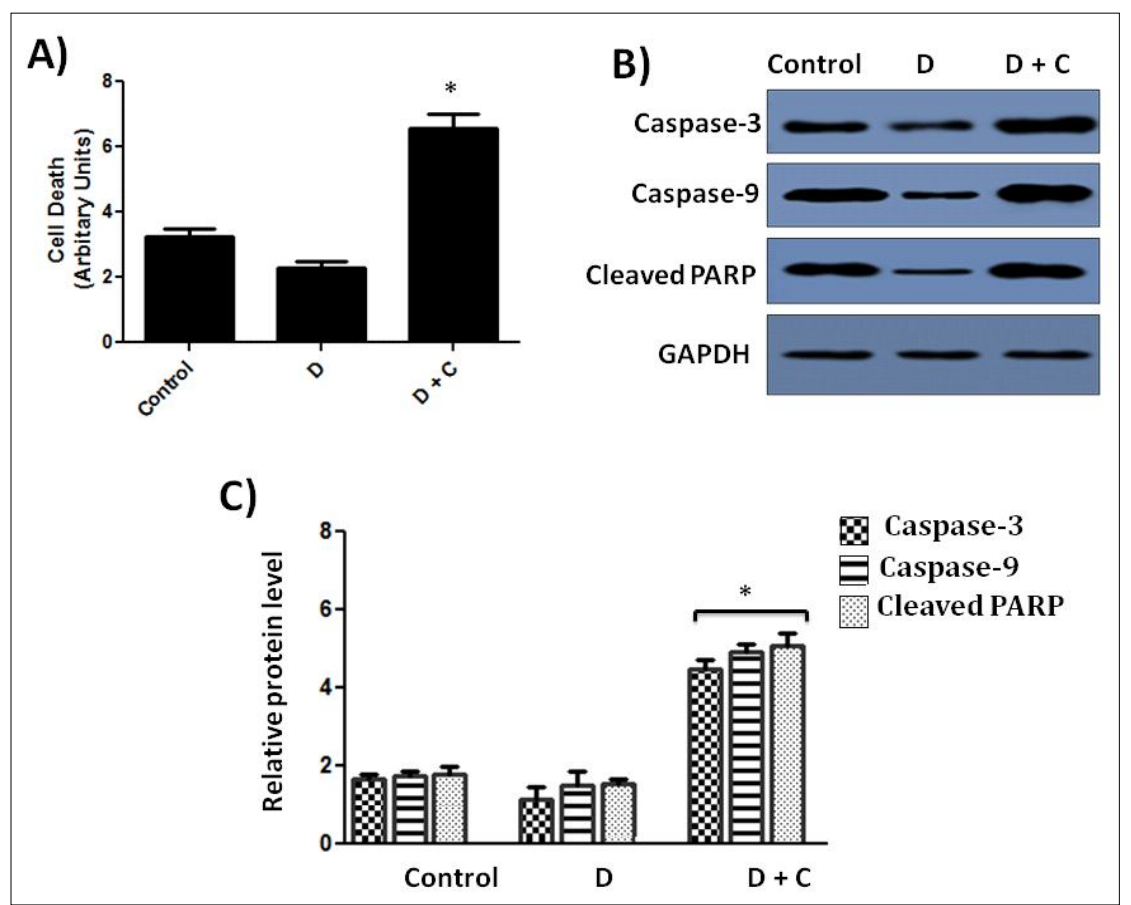

Fig 2: Effect of $\beta$-Caryophyllene on $A 549$ cell apoptotic death and pro-apoptotic proteins. The A549 cells were incubated with either dexmedetomidine or together with $\beta$-Caryophyllene for $24 \mathrm{~h}$. ELISA based apoptotic assay was carried out to determine $\beta$-Caryophyllene-induced apoptosis (Fig 2A). Expression analysis of pro-apoptotic proteins was carried out using immunoblotting

(Fig 2B). GAPDH was used as an internal control. Fig $2 \mathrm{C}$ shows densitometry analysis of pro-apoptotic proteins. 


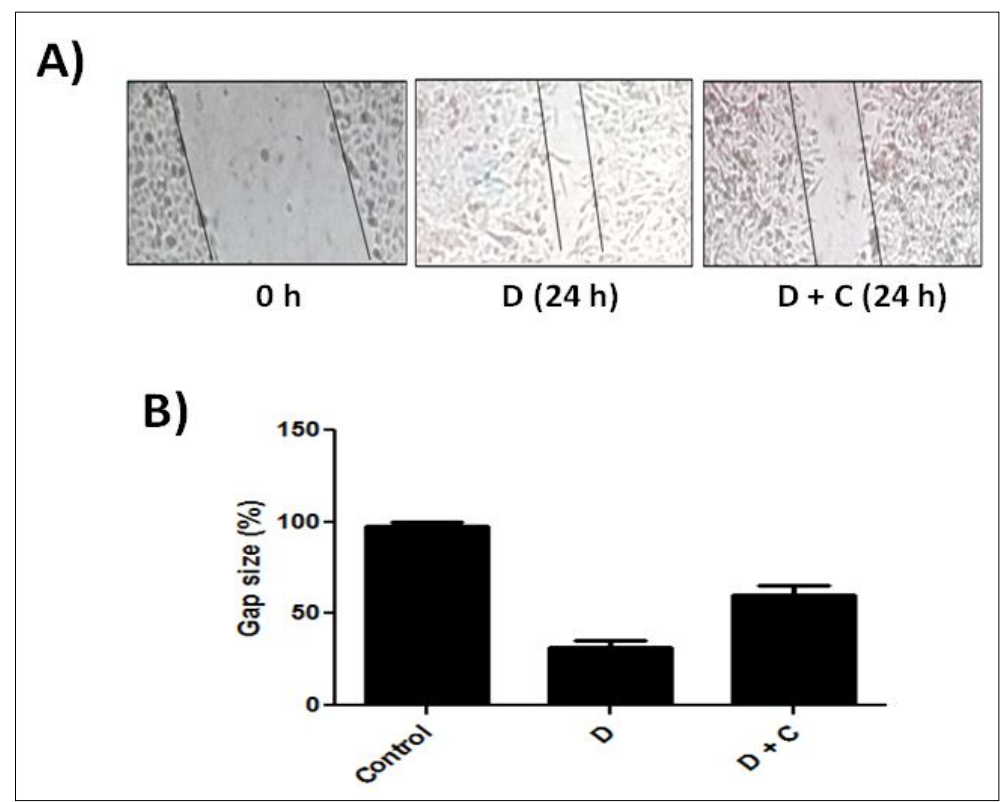

Fig 3: Effect of $\beta$-Caryophyllene on $A 549$ cell migration. Where (C) shows scratch at time $(0 \mathrm{hr})$, (D) shows closure of scratch after $24 \mathrm{~h}$ (dexmedetomidine treatment) while as $(D+C)$ shows closure of scratch after $24 \mathrm{~h}$ of $\beta$-Caryophyllene along with dexmedetomidine (Fig 3A). As shown in the Fig 3B, $\beta$-Caryophyllene is able to inhibit cell migration of A549 cells by $22 \%$ compared to dexmedetomidine treatment alone.

expression levels of cleaved PARP by 4 and 2 fold compared to dexmedetomidine treatment and control respectively.

\section{$\beta$-Caryophyllene prevents cell migration in dexmedetomidine treated cells}

The effects of $\beta$-Caryophyllene treatment on A549 cell migration was assessed with the wound-healing assay (Fig 3A, B). We found that the migration of A549 cells is inhibited by 2 and 1.5 folds with $\beta$-Caryophyllene treatment compared to dexmedetomidine treatment and control respectively.

\section{$\beta$-Caryophyllene causes $p$-AMPK activation in dexmedetomidine treated cells}

Various metabolic stresses induce AMP-activated protein kinase (AMPK) activation through its phosphorylation of threonine 172 (Mihaylova and Shaw 2011; He et al. 2014). AMPK activation through inhibition of the mTOR pathway leads to reduced proliferation of cells (Dowling et al., 2007; Kimura et al. 2003). To look for expression levels of $p-A M P K$, Cells were either treated with dexmedetomidine alone or together with $\beta$-Caryophyllene for $24 \mathrm{~h}$. It was observed that $\beta$-Caryophyllene treatment significantly increased expression of $p$-AMPK in dexmedetomidine treated cells (Fig $4 A$ ). Densitometry analysis (Fig 4B) showed that $\beta$ Caryophyllene treatment increases expression levels of $p$ AMPK by 3.5 and 1.7 fold respectively compared to dexmedetomidine treatment and control respectively.

$\beta$-Caryophyllene increases mitochondrial proliferation and PGC-1 $\alpha / T F A M$ expression in dexmedetomidine treated cells

Changes in copy number of mitochondrial DNA (mtDNA) have been well reported in human cancers O'Hara et al.

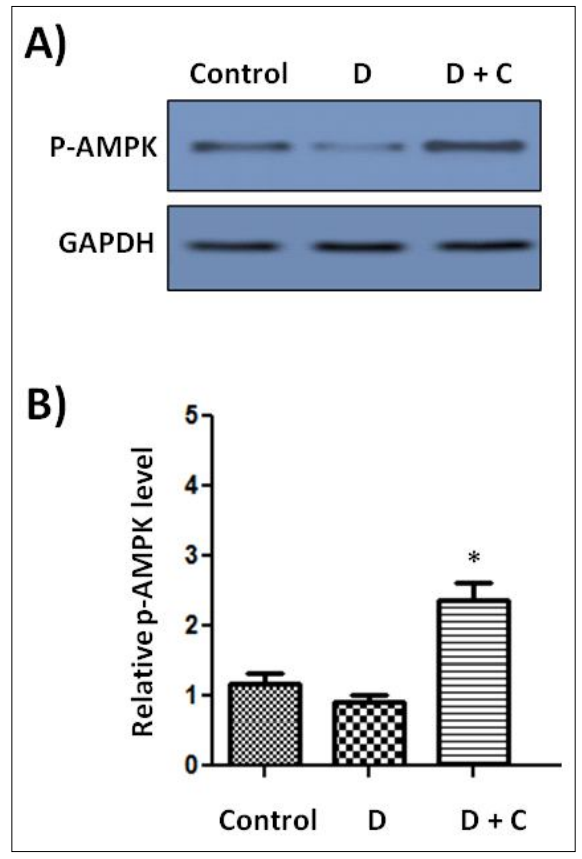

Fig 4: Effect of $\beta$-Caryophyllene treatment on p-AMPK expression. The A549 cells were either treated with dexmedetomidine alone or together with $\beta$-Caryophyllene for $24 \mathrm{~h}$. A significant increase in the expression levels of p-AMPK was observed with $\beta$-Caryophyllene treatment (Fig 4A) compared to dexmedetomidine treatment only.

Fig $4 \mathrm{~B}$ shows densitometry analysis of the blot.

(2019) Reznik et al. (2016). To look for impact of treatments on the mtDNA copies, cells were either treated with dexmedetomidine alone or together with $\beta$-Caryophyllene 


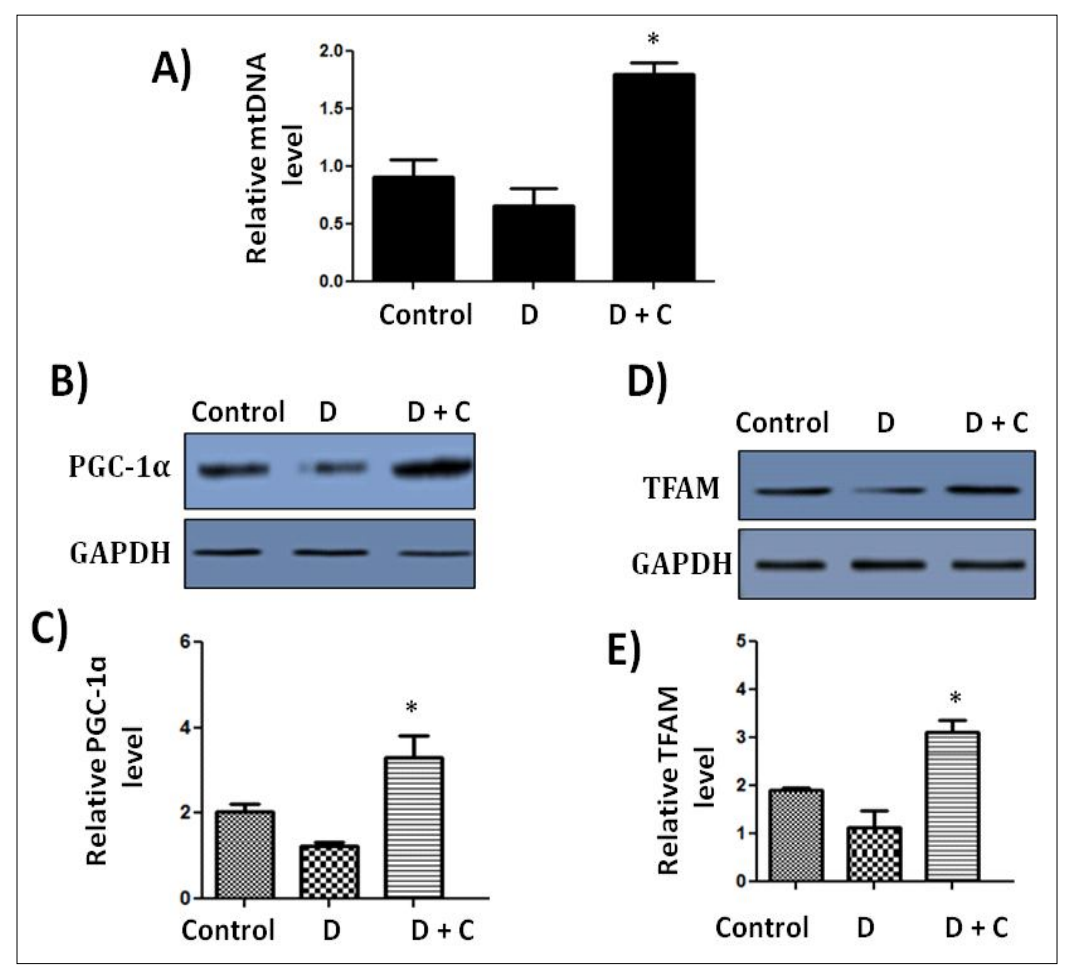

Fig 5: Effect of $\beta$-Caryophyllene treatment on mitochondrial proliferation and PGC-1 $\alpha /$ TFAM expression. The A549 cells were incubated with dexmedetomidine alone or together with $\beta$-Caryophyllene for $24 \mathrm{~h}$. An increase in mtDNA copies was observed with $\beta$ Caryophyllene treatment compared to dexmedetomidine treatment alone (Fig 5A). A significant increase in the expression levels of PGC-1Q and TFAM was observed with $\beta$-Caryophyllene treatment (Fig 5B and 5D respectively) compared to dexmedetomidine treatment alone. Fig $5 C$ and $5 D$ shows densitometry analysis of the immunoblots of $P G C-1 Q$ and TFAM respectively.

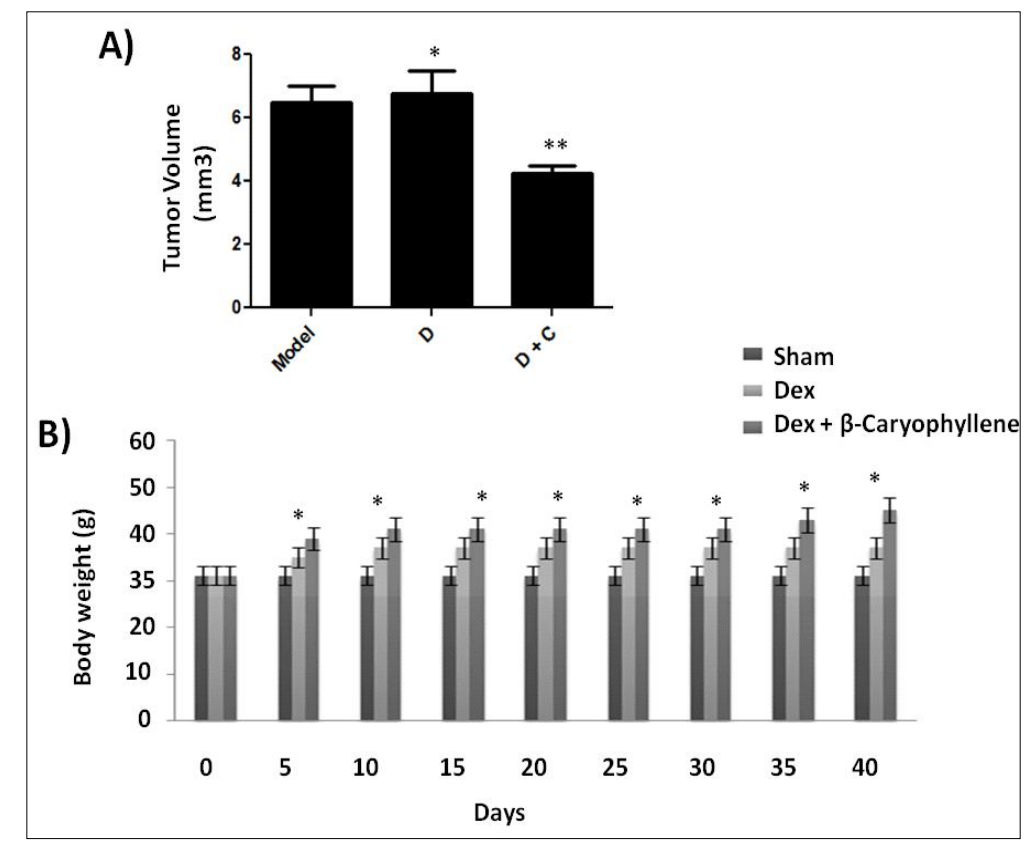

Fig 6: Effect of $\beta$-Caryophyllene on lung tumor growth in mice. A549 cells were implanted in mice followed by treatment with either dexmedetomidine alone or together with $\beta$-Caryophyllene for 40 days post implantation. Fig $6 \mathrm{~A}$ shows tumor volume $\left(\mathrm{mm}^{3}\right)$, while as Fig $6 \mathrm{~B}$ shows bogy weight $(\mathrm{g})$ post implantations. 
for $24 \mathrm{~h}$. It was found that $\beta$-Caryophyllene treatment significantly increased mtDNA copies compared to dexmedetomidine treatment (Fig 5A). Expression levels of PGC-1Q and TFAM were determined after treating cells with either dexmedetomidine alone or together with $\beta$-Caryophyllene for $24 \mathrm{~h}$. It was observed that $\beta$-Caryophyllene treatment significantly increased expression of PGC-1Q (Fig 5B) and TFAM (Fig 5D) compared to dexmedetomidine treatment only. Densitometry analysis showed that $\beta$-Caryophyllene treatment increases expression levels of PGC-1Q by 5.5 and 2.5 fold compared to dexmedetomidine treatment and control respectively (Fig 5C). Similarly, $\beta$-Caryophyllene treatment increases expression levels of TFAM by 6 and 3.5 fold respectively compared to dexmedetomidine treatment and control respectively (Fig $5 \mathrm{E}$ ).

\section{$\beta$-Caryophyllene counters dexmedetomidine associated tumor growth in lung cancer mice model}

In vivo antitumor ability of $\beta$-Caryophyllene was determined in mice model of A549 cell xenograft (Fig 6A). It was observed that $\beta$-Caryophyllene treatment of A549 cell implanted models inhibits tumor growth significantly compared to dexmedetomidine treated and control groups. However, it was observed that $\beta$-Caryophyllene treatment did not affect body weight of mice during study period (Fig 6B).

\section{CONCLUSION}

We conclude that $\beta$-Caryophyllene suppressed lung cancer cell proliferation via apoptosis through p-AMPK activation. Furthermore, mitochondrial biogenesis and expression levels of PGC-1 $\alpha$ and TFAM got up-regulated by $\beta$-Caryophyllene. Finally, $\beta$-Caryophyllene treatment of A549 cell implanted in mice model significantly reduced tumor growth. In the current study, $\beta$-Caryophyllene has emerged as an effective therapeutic agent against dexmedetomidine induced lung cancer.

\section{REFERENCES}

Amiel, E., Ofir, R., Dudai, N., Soloway, E., Rabinsky T., Rachmilevitch, S. (2012). $\beta$-Caryophyllene, a compound isolated from the biblical balm of gilead (Commiphora gileadensis), is a selective apoptosis inducer for tumor cell lines. Evidencebased Complementary and Alternative Medicine : eCAM 2012: 872394. DOI: 10.1155/2012/872394.

Araujo, L.F., Siena, A.D.D., Placa, J.R., Brotto, D.B., Barros, I.I., Muys, B.R., Biagi, C.A.O., Peronni, K.C., Sousa, J.F., Molfetta, G.A., West, L.C., West, A.P., Leopoldino, A.M., Espreafico, E.M., Silva, Jr. W.A. (2018). Mitochondrial transcription factor A (TFAM) shapes metabolic and invasion gene signatures in melanoma. Scientific Reports. 8(1): 14190. DOI: 10.1038/s41598-018-31170-6.

Bajpai, J. and Susan, D. (2016). Adjuvant chemotherapy in soft tissue sarcomas. Conflicts, consensus and controversies. South Asian Journal of Cancer. 5(1): 15-9. DOI: 10.4103/ 2278-330X.179687.
Bartke, T., Siegmund, D., Peters, N., Reichwein, M., Henkler, F., Scheurich, P., Wajant, H. (2001). p53 upregulates cFLIP, inhibits transcription of NF-kappaB-regulated genes and induces caspase-8-independent cell death in DLD-1 cells. Oncogene. 20(5): 571-80. DOI: 10.1038/sj.onc.1204124.

Canto, C. and Auwerx, J. (2009). PGC-1alpha, SIRT1 and AMPK, an energy sensing network that controls energy expenditure. Current Opinion in Lipidology. 20(2): 98-105. DOI: 10.10 97/MOL.0b013e328328d0a4.

Cragg, G.M. and Pezzuto, J.M. (2016). Natural products as a vital source for the discovery of cancer chemotherapeutic and chemopreventive agents. Medical Principles and Practice: International Journal of the Kuwait University, Health Science Centre. 25 Suppl 2: 41-59. DOI:10.1159/00044 3404.

Cui, J., Zhao, H., Wang, C., Sun, J.J., Lu, K., Ma, D. (2015). Dexmedetomidine attenuates oxidative stress induced lung alveolar epithelial cell apoptosis in vitro. Oxidative Medicine and Cellular Longevity. 2015: 358396. DOI: 10.11 55/2015/358396.

Dowling, R.J., Zakikhani, M., Fantus, I.G., Pollak, M., Sonenberg, N. (2007). Metformin inhibits mammalian target of rapamycin-dependent translation initiation in breast cancer cells. Cancer Research. 67(22): 10804-12. DOI:10.1158/0008-5472.CAN-07-2310.

Fu, B., Yin, G., Song, K., Mu, X., Xu, B., Zhang, X. (2020). Indirubin3'-Oxime (IDR3O) inhibits proliferation of osteosarcoma cells in vitro and tumor growth in vivo through AMPKactivation and PGC-1alpha/TFAM up-regulation. Doklady. Biochemistry and Biophysics. 495(1): 354-360. DOI: 10.1134/S1607672920060022.

Graham, J.G., Quinn, M.L., Fabricant, D.S., Farnsworth, N.R. (2000). Plants used against cancer - an extension of the work of Jonathan Hartwell. Journal of Ethnopharmacology. 73(3): 347-77. DOI: 10.1016/s0378-8741(00)00341-X.

He, G., Zhang, Y.W., Lee, J.H., Zeng, S.X., Wang, Y.V., Luo, Z., Dong, X.C., Viollet, B., Wahl, G.M., Lu., H. (2014). AMPactivated protein kinase induces $\mathrm{p} 53$ by phosphorylating MDMX and inhibiting its activity. Molecular and Cellular Biology. 34(2): 148-57. DOI: 10.1128/MCB.00670-13.

Hsu, S., Singh, B., Schuster, G. (2004). Induction of apoptosis in oral cancer cells: agents and mechanisms for potential therapy and prevention. Oral Oncology. 40(5): 461-73. DOI: 10.1016/j.oraloncology.2003.09.012.

Kimura, N., Tokunaga, C., Dalal, S., Richardson, C., Yoshino, K., Hara, K., Kemp, B.E., Witters, L.A., Mimura, O., Yonezawa, K. (2003). A possible linkage between AMP-activated protein kinase (AMPK) and mammalian target of rapamycin (mTOR) signalling pathway. Genes to cells : Devoted to Molecular and Cellular Mechanisms. 8(1): 65-79. DOI: 10.1046/j.1365-2443.2003.00615.x.

LeBleu, V.S., O'Connell, J.T., Gonzalez Herrera, K.N., Wikman, H., Pantel, K., Haigis, M.C., de Carvalho, F.M., Damascena, A., Domingos Chinen, L.T., Rocha, R.M., Asara, J.M., Kalluri, R. (2014). PGC-1alpha mediates mitochondrial biogenesis and oxidative phosphorylation in cancer cells to promote metastasis. Nature Cell Biology. 16(10): 9921003. DOI: $10.1038 /$ ncb3039. 
Liu, R., Fu, C., Sun, J., Wang, X., Geng, S., Zou, J., Bi, Z., Yang, C. (2017). A new perspective for osteosarcoma therapy: Proteasome inhibition by MLN9708/2238 successfully induces apoptosis and cell cycle arrest and attenuates the invasion ability of osteosarcoma cells in vitro. Cellular Physiology and Biochemistry: International Journal of Experimental Cellular Physiology, Biochemistry and Pharmacology. 41(2): 451-465. DOI:10.1159/000456598.

Masuike, Y., Tanaka, K., Makino, T., Yamasaki, M., Miyazaki, Y., Takahashi, T., Kurokawa, Y., Nakajima, K., Mori, M., Doki, Y. (2018). Esophageal squamous cell carcinoma with low mitochondrial copy number has mesenchymal and stemlike characteristics and contributes to poor prognosis. PloS one. 13(2): e0193159. DOI: 10.1371/journal.pone. 0193159.

Mihaylova, M.M. and Shaw, R.J. (2011). The AMPK signalling pathway coordinates cell growth, autophagy and metabolism. Nature Cell Biology 13(9): 1016-23. DOI:10.1038/ncb2329.

O'Hara, R., Tedone, E., Ludlow, A., Huang, E., Arosio, B., Mari, D., Shay, J.W. (2019). Quantitative mitochondrial DNA copy number determination using droplet digital PCR with single-cell resolution. Genome Research 29(11):18781888. DOI: $10.1101 / \mathrm{gr} .250480 .119$.

Puigserver, P., Wu, Z., Park, C.W., Graves, R., Wright, M., Spiegelman, B.M. (1998). A cold-inducible coactivator of nuclear receptors linked to adaptive thermogenesis. Cell. 92(6): 829-39. DOI: 10.1016/s0092-8674(00)81410-5.
Reznik, E., Miller, M.L., Senbabaoglu, Y., Riaz, N., Sarungbam, J., Tickoo, S.K., Al-Ahmadie, H.A., Lee, W., Seshan, V.E., Hakimi, A.A., Sander, C. (2016). Mitochondrial DNA copy number variation across human cancers. eLife. 5 . DOI:10.7554/eLife.10769.

Scarpulla, R.C. (2011). Metabolic control of mitochondrial biogenesis through the PGC-1 family regulatory network. Biochimica et Biophysica Acta. 1813(7): 1269-78. DOI: 10.1016/ j.bbamcr.2010.09.019.

Wang, C., Datoo, T., Zhao, H., Wu, L., Date, A., Jiang, C., Sanders, R.D., Wang, G., Bevan, C., Ma, D. (2018). Midazolam and dexmedetomidine affect neuroglioma and lung carcinoma cell biology in vitro and in vivo. Anesthesiology. 129(5): 1000-1014. DOI:10.1097/ALN.0000000000002401.

Xia, M., Ji, N.N., Duan, M.L., Tong, J.H., Xu, J.G., Zhang, Y.M., Wang, S.H. (2016). Dexmedetomidine regulate the malignancy of breast cancer cells by activating alpha2adrenoceptor/ERK signaling pathway. European Review for Medical and Pharmacological Sciences. 20(16): 3500-6.

Xie, H., Lev, D., Gong, Y., Wang, S., Pollock, R.E., Wu, X., Gu, J. (2013). Reduced mitochondrial DNA copy number in peripheral blood leukocytes increases the risk of soft tissue sarcoma. Carcinogenesis. 34(5): 1039-43. DOI: 10.1093/carcin/bgt023.

Waza, A.A. andrabi, K., Hussain, M.U (2012). Adenosine-triphosphatesensitive $\mathrm{K}+$ channel (Kir6.1): a novel phosphospecific interaction partner of connexin 43 (Cx43). Experimental Cell Research. 318(20): 2559-66. DOI:10.1016/j.yexcr. 2012.08.004 